\title{
Políticas públicas de saúde do trabalhador: análise da implantação de dispositivos de institucionalização em uma cidade brasileira
}

\author{
Public health policies for workers: analysis of the implementation \\ of institutionalization measures in a Brazilian city
}

Luís Henrique da Costa Leão ${ }^{1}$

Alexandre de Carvalho Castro ${ }^{2}$

${ }^{1}$ Escola Nacional de Saúde Pública, Fundação Oswaldo Cruz. Av. Leopoldo Bulhões 1480 , Manguinhos.

21041-210 Rio de Janeiro RJ.luis_leao@hotmail.com ${ }^{2}$ Programa de PósGraduação em Tecnologia, Centro Federal de Educação Tecnológica Celso Suckow da Fonseca (CEFET/RJ).

\begin{abstract}
The creation of the Brazilian Network of Comprehensive Occupational Health Care (Renast) in 2002 led to the appearance and increase of Reference Centers for Occupational Health (Cerest) in Brazil. In the North Fluminense Region, Cerest was inaugurated in 2006 and resulted from the transformation of the former Occupational Health Program of the city of Campos dos Goytacazes. In the broader context of the history of Occupational Health Programs in Brazil and the creation of Renast, this research analyzes the setting up of this Cerest in Campos in the State of Rio de Janeiro. In line with Foucault, it examines the specificity of its relations of provenance and emergence, conducting a review of the trajectory of the Occupational Health Program in the city in question. Documentary analysis, participant observation and interviews with Cerest team members were used as research tools. The survey revealed some political and social trouble spots. The results show that Cerest has a history of isolation and marginalization in the region's political and institutional structure. It acts continuously with a predominant logic of care since its inception, but it has faced serious political obstacles over the course of time in the implementation of actions to promote occupational health.
\end{abstract}

Key words Worker's health, Public health policies, Renast, Cerest
Resumo A criação da Rede Nacional de Atenção Integral à Saúde do Trabalhador (Renast), em 2002, fez surgir e ampliar o número de Centros de Referência em Saúde do Trabalhador (Cerest) no Brasil. Na Região Norte Fluminense, o Cerest foi inaugurado em 2006 e resultou da transformação do antigo Programa de Saúde do Trabalhador (PST) da cidade de Campos dos Goytacazes. Esta pesquisa analisa, sob o horizonte mais amplo da história dos Programas de Saúde do Trabalhador no Brasil e do surgimento da Renast, a implantação desse Cerest de acordo com a especificidade de suas relações de proveniência e emergência, conforme Foucault, fazendo um resgate da trajetória do Programa de Saúde do Trabalhador do referido município. Como instrumentos foram utilizados análise documental, observação participante e entrevistas com os membros da equipe. Nesse sentido traz à tona alguns pontos problemáticos de cunho político e social. Os resultados permitem dizer que o Cerest possui uma história de isolamento e marginalidade na estrutura politica $e$ institucional da região, atua continuamente numa lógica predominantemente assistencial desde sua criação, e enfrenta sérios entraves politicos, ao longo do tempo, na implementação das ações de saúde do trabalhador.

Palavras-chave Saúde do trabalhador, Politicas públicas em saúde, Renast, Cerest 


\section{Introdução}

A investigação sobre a saúde do trabalhador constitui uma importante área de estudos acadêmicos, inclusive em função de a temática comportar abordagens variadas e interdisciplinares. Assim, um dado fundamental que precisa ser ressaltado é que a orientação adotada nesta pesquisa implica a análise da saúde do trabalhador através da problematização do desenvolvimento de estratégias políticas que fizeram surgir dadas estruturas institucionais.

Alguns dispositivos atualmente assumem relevância e notoriedade, como é o caso dos Centros de Referência em Saúde do Trabalhador (Cerest), principalmente após a criação da Rede Nacional de Atenção Integral à Saúde do Trabalhador (Renast). Como expressão de uma dada política de saúde, esses dispositivos de saúde do trabalhador refletem o saber técnico-científico e a correlação das forças sociais em certos momentos históricos, consequentemente tais aspectos apontam a relevância de se estudar a saúde do trabalhador no âmbito de suas vinculações institucionais, históricas e sociais.

O que se verifica, entretanto, é que se por um lado a saúde do trabalhador, como campo de pesquisa interdisciplinar que comporta diversas perspectivas de análises das relações saúde/trabalho, suscita grande interesse, o estudo objetivo dos Cerest e da Renast ainda não mobiliza muitos pesquisadores. Um levantamento bibliográfico em artigos de periódicos nacionais e internacionais indexados nas bases de dados Lilacs ${ }^{1}$, Scielo $^{2}$, Scopus ${ }^{3}$, PubMed $^{4}$, Periódicos Capes ${ }^{5}$ e Ibecs ${ }^{6}$ - a partir dos descritores "saúde do trabalhador", "Cerest", e "Renast" - mostra tal descompasso, posto que, em artigos publicados entre 2002 e maio de 2010, revela, excluídas as redundâncias, apenas 10 artigos para os descritores "Cerest" e "Renast". A Tabela 1, a seguir, permite uma melhor visualização dessa assimetria nos estudos sobre a temática da saúde do trabalhador.

Devido a essas premissas, e a fim de suprir parte dessas lacunas, esta pesquisa teve como objetivo analisar, através do desvelamento das relações foucaultianas de proveniência e emergência presentes em sua organização, a implantação do Centro de Referência em Saúde do Trabalhador (Cerest), no município de Campos dos Goytacazes, no estado do Rio de Janeiro.

Assim, o referencial teórico aludido em face de tal objetivo de estudo se baseou preponderantemente em Michel Foucault ${ }^{7}$, autor que permite a análise do desenvolvimento de dispositivos de saúde do trabalhador dentro de uma ótica da his-
Tabela 1. Estudos sobre a temática da saúde do trabalhador 2002/2010.

\begin{tabular}{lcc}
\hline \multicolumn{1}{c}{$\begin{array}{c}\text { Bases } \\
\text { de Dados }\end{array}$} & $\begin{array}{c}\text { Resultados } \\
\text { para Cerest } \\
\text { e Renast }\end{array}$ & $\begin{array}{c}\text { Resultados } \\
\text { para Saúde do } \\
\text { Trabalhador }\end{array}$ \\
\hline Lilacs & 7 & 1053 \\
Scielo & 8 & 191 \\
Scopus & 0 & 45 \\
PubMed & 0 & 75 \\
Portal Periódicos Capes & 0 & 512 \\
Ibecs & 0 & 198 \\
\hline
\end{tabular}

Fonte: Autores.

tória-problema, em substituição à noção de história-continuidade. Principalmente porque o que está em jogo não é meramente a questão de qual instituição supostamente precedeu linearmente uma outra, tida como posterior.

Longe desses mecanismos de causa-efeito, a genealogia foucaultiana incorpora dois conceitos muito úteis para a indagação crítica acerca do Cerest de Campos dos Goytacazes. A questão da "proveniência" impede a busca infrutífera de marcos inaugurais que hipoteticamente explicariam uma dada essência do Cerest, justamente por preconizar a necessidade de se demarcar os acidentes de percurso e as inversões de trajetórias. O conceito de "emergência", por sua vez, desautoriza o olhar ingênuo que imagina linhas de permanência e continuidade, entre políticas de saúde e cronologias históricas. Até porque - há de se considerar - um dispositivo de saúde do trabalhador que emerge em determinada conjuntura poderia se configurar de forma totalmente distinta em outro contexto ou ocasião, em decorrência da descontinuidade de enfrentamentos sociais dos mais variados aspectos.

Assim sendo, sob o horizonte mais amplo da história dos programas de saúde do trabalhador (PST) no Brasil, este artigo faz um resgate da trajetória (jamais considerada como uma linha contínua de acontecimentos cumulativos) do programa de saúde do trabalhador do referido município, evidenciando sua nova configuração no contexto da Renast. Nesse sentido, a abordagem aqui apresentada tanto pontua as particularidades do processo de estruturação dos serviços e ações em saúde do trabalhador na região Norte Fluminense, quanto traz à tona alguns pontos problemáticos, de cunho político e social.

A emergência desses dispositivos - quando se pensa a história dos saberes e práticas em saúde do trabalhador - é de grande importância, pelo 
fato de permitir a análise das relações entre as transformações históricas da sociedade brasileira e as modalidades de atenção à saúde dos trabalhadores. Sobretudo porque, conforme já destacado, apesar de a Renast ser atualmente a principal estratégia política da área de saúde do trabalhador no Brasil, no contexto do Sistema Único de Saúde (SUS), ainda são poucos os estudos que analisam a sua história e as particularidades de implantação dos Cerest nas diversas regiões do Brasil. A investigação das singularidades regionais e especificidades da criação e desenvolvimento desses centros ao redor do país, portanto, pode até deflagrar um conjunto de elementos fundamentais para a avaliação da organização e funcionamento da Renast, como uma estratégia nacional.

Face à complexidade do cenário brasileiro, a presente pesquisa se limitou à situação que se estabeleceu especificamente no município de Campos dos Goytacazes, no Rio de Janeiro, com base em uma metodologia predominantemente qualitativa, constituindo um estudo exploratório-descritivo através da observação participante, realização de entrevistas semiestruturadas e análise documental que incluiu os relatórios de conferências de saúde, o regimento interno da comissão gestora do Cerest, os primeiros documentos balizadores do trabalho do PST, e os relatórios de trabalho da equipe do Cerest.

Dentro desse procedimento metodológico, convém destacar que as visitas ao Cerest foram feitas, em primeiro lugar, para conhecer a equipe de profissionais e a dinâmica organizacional, as tarefas e as funções, através da observação do cotidiano do trabalho, no período desde o início de 2008 até maio de 2010. Foram realizadas também entrevistas semiestruturadas com a equipe do Cerest. Estas se deram na própria sede da secretaria municipal de saúde do município de Campos dos Goytacazes (onde se localizava o Cerest), e contaram com a participação de 2 coordenadores, 4 técnicos e 2 auxiliares administrativos.

$O$ roteiro das entrevistas, elaborado previamente, enfocava temas como "história do Cerest em Campos", "principais demandas e dificuldades para o desenvolvimento das ações em saúde do trabalhador na região" e "implicações da transformação do PST em Cerest”. Todos os dados foram analisados em profundidade, mas as declarações dos entrevistados não foram transcritas no corpo do texto, a fim de evitar eventuais identificações.

O tempo de duração da pesquisa de campo foi circunstanciado pela decisão, em 27 de maio de 2010, do Tribunal Regional Eleitoral de cassar o mandato da prefeita de Campos dos Goytacazes e convocar novas eleições para o município, fato que os pesquisadores tomaram como elemento delimitador do recorte da investigação.

Nesse período, de 2008 a 2010, as altercações políticas também provocaram mudanças. Alguns funcionários do Cerest mudavam em função do grupo gestor da prefeitura, porque a maioria dos profissionais era contratada mediante indicação, sendo apenas alguns concursados.

Certos integrantes, no entanto, atuavam nos serviços de saúde desde os primeiros anos de implantação do Programa de Saúde do Trabalhador do município, sendo os fundadores do próprio PST. Estes contribuíram com dados, informações, histórias e documentos fundamentais para a pesquisa.

A ideia desses percursos metodológicos era indagar pela perspectiva da saúde do trabalhador em Campos dos Goytacazes. Principalmente porque esse Cerest está inserido em uma região recorrentemente marcada pela exploração de mão de obra barata, mormente do cortador de cana, como inclusive evidencia o episódio - ocorrido praticamente na mesma época em que esta pesquisa de campo estava sendo realizada - em que a ação do Ministério Público do Trabalho, em 2009, identificou 280 trabalhadores (entre eles quatro adolescentes), em condições de trabalho análogas à escravidão, numa área que produzia cana de açúcar para uma usina da região ${ }^{8}$.

\section{Dos programas de saúde do trabalhador à Renast}

A atenção dirigida à saúde dos trabalhadores tem antecedentes históricos que, segundo alguns autores, podem remontar aos médicos incumbidos de visitar ambientes de trabalho insalubres no início da Revolução Industrial ${ }^{9}$. Para o escopo deste trabalho, com um recorte muito mais definido, basta dizer que a saúde do trabalhador mantém relações de proveniência com a luta dos trabalhadores pelo direito à saúde, no bojo da Reforma Sanitária Brasileira e com inspiração no Movimento Operário Italiano ${ }^{10}$. Dentro desse quadro, a publicação de obras de autores italianos como Giovanni Berlinguer, Medicina e Política $^{11}$ e A Saúde nas Fábricas ${ }^{12}$ e Ivar Oddone et al., Ambiente de Trabalho: A Luta dos trabalhadores pela saúde $e^{13}$ teve papel fundamental na constituição desse novo 'saber-fazer' sobre as relações saúde-trabalho no Brasil.

O intercâmbio entre sindicatos brasileiros e alguns militantes da Reforma Sanitária Italiana, que resultou na vinda do próprio Giovanni Berlinguer ao Brasil, foi um incentivo para a realização das semanas de saúde do trabalhador (SE- 
MSAT), ocorridas em São Paulo, e para a criação do Departamento Intersindical de Estudos e Pesquisas de Saúde e dos Ambientes de Trabalho (DIESAT), que cumpriu importante papel no processo de luta dos trabalhadores pela saúde no Brasil. A partir dos anos 1980 surgiram diversas outras iniciativas em direção à saúde do trabalhador, pois setores do movimento sindical (como metalúrgicos e petroquímicos) começaram a exigir dos serviços de saúde pública maior envolvimento com questões de saúde relacionadas ao trabalho. Como marco desse processo, foram criados os pioneiros Programas de Saúde do Trabalhador no âmbito da rede pública de saúde, em resposta à demanda dos sindicalistas, em vários lugares do Brasil, primeiro em São Paulo, pouco depois nos estados de Minas Gerais, Rio de Janeiro, Rio Grande do Sul e Bahia ${ }^{14}$.

Em que pese o valor de todas essas iniciativas brasileiras, é necessário ressaltar, contudo, que a preocupação com a saúde do trabalhador, nesse momento, não era exclusividade nacional. O que havia, na verdade, era uma tendência mundial, tendo a Organização Mundial de Saúde (OMS) através da Organização Pan-Americana da Saúde (OPAS), inclusive proposto a organização de ações direcionadas aos trabalhadores como objeto de política pública de saúde. "A importância do assunto levou a OPAS, em 1983, a reunir um grupo de consultores incumbido de preparar um documento básico sobre o tema. Os quais elaboraram um 'Programa de Saúde do Trabalhador', cujo objetivo geral é o de contribuir para a proteção e a promoção da saúde dos trabalhadores, através do desenvolvimento ou do reforço, a nível nacional, dos programas de saúde cuja cobertura e conteúdo permitam a identificação, a avaliação e o controle eficiente de fatores e condições relacionadas ao trabalho e que sejam responsáveis por efeitos adversos sobre a saúde"15.

A Organização Internacional do Trabalho (OIT), por sua vez, propunha por meio da convenção 161, em 1985, o desenvolvimento de serviços de saúde no trabalho, como políticas nacionais, com participação dos trabalhadores e seus representantes, como preconiza o modelo tripartite.

A particularidade brasileira, no entanto, decorreu do fato de que no país formou-se uma Assembleia Constituinte, razão pela qual a própria Constituição Federal de $1988^{16}$ - no artigo 200, em seus incisos II e VIII - considerou o trabalho como fator determinante da saúde da população e, consequentemente, responsabilizou o Estado pela execução das ações de saúde do trabalhador.

Tais dispositivos constitucionais marcaram profundamente os desenvolvimentos dessa ques- tão no Brasil. Desta forma, o início dos anos 90 acompanhou a formulação da lei Orgânica da Saúde (Lei 8080/1990 ${ }^{17}$, que inclui ações em saúde do trabalhador), e uma proposta do Ministério da Saúde que privilegiava a organização dessas ações em Centros de Referência em Saúde do Trabalhador (Cerest), como alternativa para potencializar os escassos recursos disponíveis, facilitar o diálogo com o movimento social e capacitar profissionais para desenvolver as atividades propostas?.

Houve, portanto, no decorrer da década de 1990, um considerável crescimento e expansão das ações em saúde do trabalhador, tornandose uma época fértil em experiências de PST e Cerest, mas que enfrentavam problemas como isolamento, pouco financiamento e baixa cobertura de ações. O campo saúde do trabalhador tem ocupado lugar periférico e marginal na configuração institucional do SUS ${ }^{18}$.

No final da década de 1990 e início de 2000, porém, ocorreram novos desenvolvimentos numa tentativa de organizar e sistematizar as experiências dos PST e Cerest, e incrementar a área de saúde do trabalhador no SUS. A partir de uma revisão crítica das experiências dos PST, vinha sendo gestada no Ministério da Saúde a ideia da criação de uma rede que pudesse ser elemento integrador desses diversos centros e programas. Assim, após um período de debates internos ${ }^{18}$, o Ministério da Saúde, por meio a portaria no 1.679 , criou a Rede Nacional de Atenção Integral à Saúde do Trabalhador (Renast), a fim de estruturar e normatizar a habilitação e o convênio entre os municípios, estados e o Ministério da Saúde para a implantação dos Cerest no território nacional ${ }^{19}$.

No ano de 2005, com a publicação da portaria no 2.437 no dia 7 de dezembro, objetivou-se ampliar e fortalecer a Renast, através da organização de serviços e municípios sentinelas, da implementação de ações de vigilância e promoção da saúde, do fortalecimento do controle social e da mudança nas cifras de financiamento para os Cerest estaduais e regionais. Segundo o documento, os Cerest deveriam ser polos irradiadores de uma concepção onde a categoria "trabalho" constituiria fator preponderante nas relações de saúde/doença ${ }^{20}$.

Como fruto do esforço permanente de fortalecer a implantação da Renast de forma articulada entre as esferas de governo federal, estadual e Distrito Federal, e municipal foi feita outra revisão, em 2009, sendo publicada uma nova portaria, no 2.728 de 11 de novembro. Segundo este documento, o Cerest tem a finalidade de "dar subsídio técnico para o SUS, nas ações de pro- 
moção, prevenção, vigilância, diagnóstico, tratamento e reabilitação em saúde dos trabalhadores urbanos e rurais" 21 .

Assim, a Renast, por meio dos Cerest, visa implantar uma lógica de trabalho nos municípios brasileiros baseada na construção de dinâmicas intra e intersetoriais no intuito de prover ações de assistência e vigilância em saúde do trabalhador, em colaboração com os órgãos públicos e sindicatos de trabalhadores ${ }^{22}$.

Esse breve panorama histórico do surgimento e desenvolvimento das ações e serviços de saúde do trabalhador no Brasil, especialmente dos Cerest, a partir dos iniciais Programas de Saúde do Trabalhador até à Renast, não deve, todavia, ser considerado como uma evolução linear. Mas, ao contrário, ser concebido como uma genealogia. O que significa igualmente dizer que o processo de implantação dos Cerest em várias regiões do Brasil também não deve ser visto de modo uniforme, sendo efetivamente necessário desenvolver e aprofundar investigações específicas, como a apresentada a seguir sobre Campos dos Goytacazes.

\section{O Cerest em Campos dos Goytacazes}

É necessário enfatizar que o processo de implantação do Centro de Referência em Saúde do Trabalhador na cidade de Campos dos Goytacazes possui dinâmicas muito peculiares de proveniência, devido às características do Norte Fluminense. Destarte, as primeiras ações direcionadas para a saúde dos trabalhadores na cidade remontam à década de 1970, quando existia atendimento aos trabalhadores em setores do hospital da Sociedade Portuguesa de Beneficência, do Hospital dos Plantadores de Cana e da Santa Casa de Misericórdia de Campos. Tais ações possuíam caráter curativo, evidenciando uma lógica meramente assistencial, cujo foco era a doença. Esse modelo predominou até a década de 1990, quando de forma lenta, mas progressiva, surgiram novas preocupações com a efetiva relação entre saúde e trabalho, a partir da perspectiva teórica das relações processo de trabalho e processo de saúde/doença, característica da saúde do trabalhador, que vinha se expandindo no Brasil. Paralelamente, existiam as ações dos Serviços Especializados em Engenharia de Segurança e de Medicina do Trabalho (SESMT), que eram também assistencialistas, e o trabalho das Comissões Internas de Prevenção de Acidentes (CIPA) que, comandadas pelos empregadores, tinham pouco a contribuir por ser um modelo patronal ${ }^{23}$.

Nesse contexto de críticas ao modelo assistencialista e patronal, reflexo das novas posturas teórico/político/legais do Estado brasileiro advindas da Reforma Sanitária e do movimento dos trabalhadores, alguns interessados nessas questões se articularam na I Conferência Municipal de Saúde em prol da saúde do trabalhador, realizada em Campos no ano de 1991. Na ocasião, foram feitas propostas fundamentais para a implantação das ações de saúde do trabalhador no município, tais como: a realização de atividades de educação em saúde do trabalhador, organização do programa de saúde do trabalhador, incentivo ao entrosamento dos setores saúde, trabalho e previdência, e estruturação do Conselho Municipal de Saúde do Trabalhador ${ }^{24}$. Entretanto, apenas dois anos depois, em 1993, com a realização da II Conferência Municipal de Saúde, é que foram efetivamente lançadas as bases - os objetivos, a forma de gestão e a estruturação - para a criação e a operacionalização do programa de saúde do trabalhador ${ }^{25}$.

Assim, o PST conseguiu um espaço físico para se estruturar e deu os primeiros passos: organizou um sistema de informação em saúde do trabalhador, iniciou o atendimento a acidentados do trabalho, estabeleceu parcerias com sindicatos (formando conselho gestor), e desenvolveu ações educativas e preventivas em diversas empresas. Além disso, passou a interagir com o Conselho Regional de Serviço Social (CRESS), o Tribunal Regional do Trabalho - Junta de Conciliação e Julgamento (TRT), a Delegacia Regional do Trabalho (DRT), o Instituto Nacional do Seguro Social (INSS) e, enfim, com a sociedade civil organizada ${ }^{23}$.

Ocorre que, oficialmente, o PST de Campos foi instituído apenas em 1997, por meio da lei municipal no 6.397 e ratificado no decreto de $n^{\circ}$ 45/98, que previa a organização da Comissão Gestora a ser formada com o objetivo de ser um fórum interinstitucional de cogestão da coordenação do PST (além de exercer o controle social das ações do PST $)^{26}$.

Dessa forma, segundo a perspectiva da emergência foucaultiana, esse intervalo de seis anos que vai da realização da I Conferência Municipal de Saúde à oficialização do Programa - tem importância capital, pois indica a luta dos atores do PST em favor de sua institucionalização. O surgimento de um programa cuja base ideológica clamava por transformação na realidade e cujo objetivo era analisar e intervir nas relações entre os processos produtivos da região e a saúde dos trabalhadores, claramente enfrentou oposição de setores conservadores, gestores da saúde, organizações políticas e sindicais aliados ao Capital (empresários, usineiros, etc.). Para se institucio- 
nalizar, portanto, o PST teve que entrar num campo de lutas entre forças radicalmente opostas, enfrentando a hegemonia de práticas de políticas públicas em aliança com o poder do capital local.

Assim, o PST, uma vez criado, tinha a missão de ser um serviço de promoção à saúde dos trabalhadores, sem importar o tipo de vínculo empregatício (pois incluía trabalhadores de empresas privadas, públicas, autônomos, informais), para prevenir doenças e acidentes decorrentes do trabalho, através de medidas que controlavam os riscos existentes, eliminando-os ou reduzindo-os. Suas principais atividades seriam: (a) a vigilância epidemiológica e sanitária para estudo e controle dos riscos e agravos à saúde do trabalhador; (b) a orientação, acompanhamento e/ou encaminhamento dos trabalhadores vítimas de acidentes ou doenças decorrentes do trabalho (bem como a consequente recuperação e a reabilitação); e (c) a fiscalização e controle das condições de produção e dos riscos de acidentes e/ou doenças decorrentes do trabalho ${ }^{27}$.

Esse PST, entretanto, depois de sete anos sofreu novos desenvolvimentos, pois o - até então - programa de saúde do trabalhador tornou-se Centro de Referência em Saúde do Trabalhador, de cunho regional, no ano de 2006, devido à expansão da Renast. O processo de mudança resultou das negociações na Comissão Intergestora Bipartite, entre a Secretaria de Estado de Saúde e Defesa Civil do Rio de Janeiro (SESDEC-RJ) e a Secretaria Municipal de Saúde de Campos (SMS-Campos). De acordo com o planejamento da SESDEC-RJ, seguindo a lógica da regionalização do SUS, o estado do Rio de Janeiro devia ser segmentado em regiões a fim de serem escolhidas algumas cidades, com população superior a um milhão de pessoas, para a implantação de alguns Cerest. Na ocasião, o município de Campos dos Goytacazes possuía apenas cerca de quinhentos mil habitantes, mas ao serem somadas as populações das cidades circunvizinhas, como São Francisco do Itabapoana e Macaé, o número ultrapassava um milhão.

Desta forma, e por causa de tal contingência, Campos foi escolhida como cidade chave para implantação do Cerest Regional, de acordo com o parecer da Comissão Intergestora Bipartite. Assim, mediante a concordância tanto da Secretaria Municipal de Saúde, quanto da equipe do PST, as mudanças foram instituídas pela publicação da portaria no 614 de 17 de agosto de 2006, da Secretaria de Atenção à Saúde do Ministério da Saúde e registrada no Diário Oficial da União, em Setembro de 2006, oficializando a implantação do Cerest em Campos ${ }^{28}$.

\section{Discussão dos resultados da pesquisa}

A perspectiva foucaultiana sobre as relações de proveniência e emergência permite um olhar efetivamente crítico acerca da implantação do Cerest de Campos ao ressaltar tais relações nessa situação específica. Se por um lado há um discurso manifesto que relaciona esse Cerest às propostas da Renast, por outro, é possível dizer que há relações latentes que o vinculam a vícios políticos igualmente encontrados em dispositivos que o precederam.

Conforme detalhado nos tópicos anteriores, a partir de 2002, o Ministério da Saúde iniciou o projeto de implantação dos Cerest em várias secretarias de saúde, sendo que, em Campos, tal implantação ocorreu no ano de 2006, resultando na transformação do programa municipal de saúde do trabalhador, existente há anos. Essa transformação, porém, assumiu contornos meramente superficiais.

Ao focar esse PST, a pesquisa realizada através das entrevistas verificou que a constante troca do cargo de secretário de saúde do município, e consequentemente, do coordenador do PST, era uma dificuldade recorrente no programa, impedindo não só a concretização dos objetivos, mas também a fluidez das ações, propostas e acordos estabelecidos entre a equipe de saúde do trabalhador e o gestor municipal. Esses dados levantados na pesquisa também mostram que, curiosamente, embora cada gestor municipal de saúde tivesse uma prioridade no governo, todos possuíam uma coisa em comum - a não priorização das ações de saúde do trabalhador.

Nesta discussão, portanto, é fundamental deixar claro que a falta de continuidade de dados procedimentos, ou a política do "esvaziar gavetas"18 após a mudança de partidos políticos no poder, se constitui em obstáculos para a efetivação das ações de saúde do trabalhador (Quadro 1).

No que tange especificamente aos coordenadores do PST e, posteriormente, do Cerest de Campos, verificou-se que sua função e permanência no cargo dependiam basicamente do partido que estava no poder municipal, ou dos acordos entre os partidos opostos. Estes arranjos políticos persistiram mesmo após a chegada da Renast. Como exemplo, no ano de 2008, período de determinado partido no governo municipal, o Cerest esteve sob uma coordenação, que foi radicalmente substituída no ano seguinte, quando o partido de oposição venceu as eleições municipais e assumiu o poder. Deste modo, é possível perceber certa submissão da política pública de saúde do trabalhador aos interesses político-partidári- 
Quadro 1. Quadro panorâmico das políticas municipais de Campos dos Goytacazes / Mudanças no PSTCerest.

\begin{tabular}{|c|c|c|c|}
\hline 2004 & 2005 & 2006 & 2007 \\
\hline $\begin{array}{l}\text { Outubro } \\
\text { Eleições } \\
\text { Municipais }\end{array}$ & $\begin{array}{l}\text { Janeiro } \\
\text { Posse do prefeito Carlos Alberto } \\
\text { Campista (PDT) } \\
\text { Maio } \\
\text { Carlos Alberto Campista e seu vice são } \\
\text { cassados por determinação da juíza da } \\
76^{\text {a }} \text { Zona Eleitoral. O presidente da } \\
\text { Câmara Municipal Alexandre } \\
\text { Mocaiber (PDT) assume interinamente } \\
\text { até a realização de novas eleições. }\end{array}$ & $\begin{array}{l}\text { Março } \\
\text { Realização de Eleições } \\
\text { Municipais suplementares } \\
\text { Abril } \\
\text { Posse do Prefeito Alexandre } \\
\text { Mocaiber (PSB) para um } \\
\text { mandato de dois anos } \\
\text { Agosto } \\
\text { Transformação do PST em } \\
\text { Cerest }\end{array}$ & \\
\hline & 2008 & 2009 & 2010 \\
\hline \multicolumn{2}{|c|}{$\begin{array}{l}\text { Março } \\
\text { Alexandre Mocaiber (PSB) é afastado da } \\
\text { prefeitura após operação da Polícia Federal, por } \\
\text { solicitação do Ministério Público Federal } \\
\text { Abril } \\
\text { Alexandre Mocaiber (PSB) reassume cargo de } \\
\text { Prefeito por decisão do Supremo Tribunal de } \\
\text { Justiça } \\
\text { Agosto } \\
\text { Relatório do I Encontro Regional da Saúde do } \\
\text { trabalhador do Norte Fluminense: Cerest atua nos } \\
\text { moldes da assistência médica } \\
\text { Outubro } \\
\text { Eleições Municipais }\end{array}$} & $\begin{array}{l}\text { Janeiro } \\
\text { Posse da Prefeita Rosinha } \\
\text { Garotinho (PMDB) } \\
\text { Janeiro } \\
\text { Substituição da } \\
\text { Coordenação do Cerest } \\
\text { Outubro } \\
\text { Divisão Cerest/NF e PAST } \\
\text { (com profissionais do } \\
\text { extinto PST) }\end{array}$ & $\begin{array}{l}\text { Maio } \\
\text { Rosinha Garotinho } \\
\text { (PR) é cassada pelo } \\
\text { TRE e são } \\
\text { convocadas novas } \\
\text { eleições para o } \\
\text { município. }\end{array}$ \\
\hline
\end{tabular}

Fonte: Autores.

os, que acabaram por obstruir, por vezes, o caminho de uma saúde do trabalhador mais efetiva.

O que de fato ocorreu, no âmbito do PST de Campos foi uma espécie de apropriação distorcida do programa, onde a implantação desse dispositivo institucional serviu primordialmente como pretexto para distribuir empregos por indicação dos chefes políticos locais. Dessa forma, como os indicados para os cargos não necessariamente incorporavam as propostas institucionais, e o ideário do programa, o mero assistencialismo sobrepujou a vigilância epidemiológica e o controle das condições de trabalho, a despeito de esforços empreendidos por profissionais envolvidos com o movimento em prol da saúde dos trabalhadores.

Tal fato repercutiu diretamente no enquadramento das atividades do Cerest, pois as ações da prevenção, promoção e vigilância em saúde do trabalhador, por demandarem maiores articulações intra e intersetoriais, além da participação das entidades sindicais, igualmente cederam espaço para as ações médico/curativos/assistenciais. Deste modo, o foco do trabalho ao invés de ser a relação entre o processo de trabalho e a saúde, se concentrou na doença em si. Esses entraves técnico-políticos deveriam ser resolvidos com a chegada da Renast, o que de fato não aconteceu inteiramente.

As informações coletadas apontam que segundo um ponto de vista formal, quando a equipe do PST de Campos transformou-se em equipe do Cerest, incorporou novas e distintas funções e tais profissionais deixaram de estar submetidos aos planos e propostas elaboradas da Secretaria Municipal de Saúde, uma vez que se tornara um centro regional, submisso à legislação da Renast. A mudança não seria somente em relação à nomenclatura, mas de toda estrutura e proposta de trabalho, inclusive do financiamento, que passaria a ser feito por transferência do Ministério da Saúde em caráter específico para as ações de saúde do trabalhador. Todas essas injunções, todavia, não foram suficientes para sanear as distorções e os vícios que ainda permaneciam.

Em 2008 - dois anos, portanto, após a emergência do Cerest de Campos - quando da reali- 
zação do I Encontro Regional da Saúde do Trabalhador do Norte Fluminense, que contou com a presença de vários representantes dos municípios da abrangência deste Cerest, foram ressaltados alguns pontos críticos da região em relação à saúde do trabalhador: poucas ações de vigilância, fraca articulação intrassetorial, inexistência de pactos interssetoriais, baixa comunicação em saúde do trabalhador entre os municípios da região, entre outras coisas ${ }^{29}$. Isso porque a equipe do Cerest, que devia irradiar a cultura do processo de trabalho e saúde na região, estava atuando nos moldes da assistência médica.

Outras surpreendentes mudanças ocorreram em 2010 no âmbito da secretaria municipal de saúde do município de Campos, pois dentre uma série de alterações administrativo-organizacionais, foi desenvolvido o Programa de Atenção à Saúde do Trabalhador (PAST), que guardava semelhanças com o antigo e extinto PST.

Em decorrência, transformações de caráter organizacional foram verificadas no próprio Cerest, com um deslocamento de boa parte da sua equipe de profissionais para o PAST (alguns dos quais, como dito na introdução, atuaram outrora no próprio PST), ao mesmo tempo em que outros técnicos passaram a compor uma nova equipe do Cerest, inclusive, com outra coordenação.

Essa lógica de criar mais mecanismos e programas específicos teve consequências para a integralidade das ações em saúde do trabalhador, na medida em que o trabalho enquanto fator determinante da saúde da população acabou não sendo priorizado pelo sistema como um todo, mas tão somente pelos técnicos do setor responsável. Tal fragmentação na política de saúde do trabalhador não condiz com a perspectiva integradora da noção de sistema, ao mesmo tempo em que permite a criação de instâncias na esfera de governo municipal, que tendem a ser meramente de caráter eleitoreiro.

Ora, o papel do Cerest deveria ser justamente o de articular as áreas do SUS a fim de que atuassem de acordo com perspectiva da saúde do trabalhador. Ao mesmo tempo, ao Cerest caberia a função de dialogar e cooperar com diversos órgãos do governo e da sociedade civil interessados e responsáveis pelas relações de saúde-trabalho. Tais articulações não são observadas em Campos. Portanto, a falta de um reconhecimento adequado do propósito e da missão do Cerest em seu território de abrangência torna-se um sério problema, pois a equipe, uma vez dedicada a atendimentos médicos de agravos relacionados ao trabalho, tem menos possibilidade de cumprir seu papel de articuladora da rede de atenção integral.
Consequências problemáticas para o avanço das ações em saúde do trabalhador podem ser facilmente notadas. Por exemplo, a rede de serviços sentinela, que se refere à instituição e indicação de serviços de saúde do trabalhador de retaguarda, de média e alta complexidade, até então não se configurou de maneira robusta, como preconiza a Renast, o que impede a produção de informação sobre agravos de notificação compulsória nos termos da Portaria no 777 do Ministério da Saú$\mathrm{de}^{30}$. A dificuldade em produzir tais informações também dificulta o conhecimento sobre a realidade da saúde dos trabalhadores da região, não provocando maiores articulações, no âmbito municipal e regional, com as vigilâncias epidemiológica e sanitária. Além dessa fraca articulação intrassetorial, a inexistência de mecanismos sólidos de pactuação intersetorial também é observada. Apesar das intenções dos membros da equipe, até Maio de 2010, a Comissão Intersetorial de Saúde do Trabalhador Regional (CIST), por exemplo, ainda estava para ser ativada. Outra consequência é o enfraquecimento do controle social em saúde do trabalhador, devido à baixa participação dos trabalhadores e suas representações sindicais nas ações do Cerest.

Esta pesquisa, portanto, permite constatar que esse Cerest encontra dificuldades para avançar nas ações de atenção integral à saúde dos trabalhadores, numa região importante da economia brasileira que abriga setores como o petrolífero e o sucroalcooleiro. Tais problemas mantêm relações de proveniência com as práticas políticas das oligarquias da região que, independentemente das características distintivas de cada dispositivo institucional (PST ou Cerest), consideram as instituições voltadas para a saúde pública como instrumento de cooptação partidária a partir da distribuição de empregos para sua clientela eleitoral.

Nesse sentido, políticas públicas na área de saúde do trabalhador estão sendo incorporadas dentro de políticas governamentais que privilegiam o interesse privado, e não o público em si. Aspecto que comprova o fato de que políticas estatais não são necessariamente públicas. Daí a necessidade de se pensar a relação entre o Estado e as políticas públicas, já que estes termos não são coincidentes e que os domínios do Estado e do público nem sempre se justapõem ${ }^{31}$.

\section{Conclusão}

Conforme salientado, o objetivo deste artigo foi analisar, mediante um recorte do referencial teórico foucaultiano, a história da saúde do traba- 
lhador no Norte Fluminense, enfocando o surgimento do PST e posteriormente a implantação do Cerest, especificamente no município de Campos dos Goytacazes, no Rio de Janeiro.

Os resultados da pesquisa qualitativa mostraram que, a despeito de uma série de mudanças aparentes, não houve alterações substanciais na implementação de ações de saúde do trabalhador com a chegada da Renast e do Cerest. Em outras palavras, a história das ações de saúde do trabalhador em Campos dos Goytacazes - desde a fundação do Programa de Saúde do Trabalhador até à experiência da implantação do Centro de Referência em Saúde do Trabalhador - aponta paradoxalmente para o desinteresse público e entraves políticos nas ações efetivas de promoção e prevenção da saúde dos trabalhadores da região.

A investigação da proveniência histórica apontou a descaracterização do programa do PST desde sua luta por institucionalização e oficialização em 1997. E, além disso, mostrou que a emergência do Cerest, em 2006, não modificou a lógica assistencial/curativa presente na configuração das ações, fato que acabou favorecendo ao isolamento desse Cerest nas estruturas municipais e regionais de saúde, dificultando o diálogo com órgãos públicos e sindicatos, e impedindo a ampliação da Renast na região Norte Fluminense do estado do Rio de Janeiro.

Este estudo, consequentemente, aponta para as dificuldades políticas e institucionais na implantação da Renast, pois no caso do Cerest na cidade de Campos, os princípios e diretrizes da Política Nacional de Saúde do Trabalhador, tipificados na Renast, carecem de consolidação institucional, principalmente pela ênfase nas ações assistenciais em detrimento das ações de vigilância. Portanto, a criação da Renast não representa, necessariamente, uma mudança de paradigmas na configuração das ações em saúde do trabalhador, principalmente onde esses serviços estão praticamente circunscritos à assistência médica, como em Campos dos Goytacazes.

Realmente, a trajetória da Saúde do Trabalhador em Campos - desde o PST ao Cerest está eivada de contradições, pois o processo de emergência de tais dispositivos carrega em seu bojo o interesse patrimonialista de preencher cargos com indicações políticas, mormente nesse município grandemente beneficiado em seu orçamento com os royalties do petróleo. Deste modo, aquilo que poderia ser uma política pública de saúde do trabalhador no município, na prática, torna-se apenas um meio legal para configuração de ações político-partidárias.
Tais problemas de ordem ética e política apontam para a fragilidade de práticas públicas em saúde do trabalhador diante dos "vícios" político-partidários das configurações regionais. Essa problemática acaba por desencaminhar ações mais densas em saúde do trabalhador que potencialmente poderiam ser difundidas e dinamizadas por dispositivos institucionais como os Cerest.

Considerando que o enfraquecimento das instâncias de controle social sobre as ações em saúde do trabalhador e de mecanismos de fiscalização pública dos Cerest corrobora para a ocorrência dessas situações, é preciso mencionar que quanto menos o público participa ativamente do processo de implantação, ação e gestão, mais a política pública torna-se vulnerável ao jogo político-partidário.

Ainda existe muita história a ser investigada sobre os programas e serviços de saúde do trabalhador no Brasil, e o caso do Cerest na cidade de Campos, aqui analisado, enfatiza a necessidade e a importância da realização de outras pesquisas de cunho histórico para a memória da Renast no Brasil. Ademais, estudos como este podem servir, além do registro da história dos saberes e práticas de saúde do trabalhador no Brasil, como avaliação da Renast no território nacional, na medida em que indicam as dinâmicas próprias de cada região no envolvimento com as questões de saúde-trabalho.

\section{Colaboradores}

LHC Leão trabalhou na concepção inicial da pesquisa, trabalho de campo, coleta de dados, e redação preliminar do texto; AC Castro orientou a elaboração teórica e metodológica das atividades de pesquisa, contribuiu na análise e interpretação dos dados, assim como na redação final do artigo. 


\section{Referências}

1. Literatura Latino-Americana e do Caribe em Ciências da Saúde(Lilacs) [base de dados na Internet]. São Paulo: Centro Latino-Americano e do Caribe de Informação em Ciências da Saúde, LILACS - Literatura Latino-Americana e do Caribe em Ciências da Saúde. BVS Site 5.2.11 [acessado 2010 fev 22]. Disponível em: http://bases.bireme.br/cgi-bin/wxislind.exe /iah/online/

2. Scientific Electronic Library Online (Scielo Brasil) [base de dados na Internet]. São Paulo: Scientific Electronic Library Online. [acessado $2010 \mathrm{fev} 22$ ]. Disponível em: http://www.scielo.br/

3. Scopus [base de dados na Internet]. Amsterdam: Elsevier (B.V.). 2010. [acessado $2010 \mathrm{fev} 23$ ]. Disponível em: http://www.scopus.com/home.url

4. PubMed.gov [base de dados na internet]. Bethesda (MD): National Library of Medicine (US). [acessado 2010 fev 24]. Disponível em: http://www.ncbi. nlm.nih.gov/pubmed

5. O Portal Brasileiro da Informação Científica (Portal Capes) [bases de dados na Internet]. Brasília: Ministério da Educação; 2004. [acessado 2010 fev 24]. Disponível em: http://www.periodicos.capes. gov.br

6. Îndice Bibliográfico Español en Ciencias de la Salud (Ibecs) [base de dados na Internet]. São Paulo: Centro Latino-Americano e do Caribe de Informação em Ciências da Saúde, Índice Bibliográfico Español en Ciencias de la Salud. [acessado $2010 \mathrm{fev}$ 25]. Disponível em: http://ibecs.isciii.es/

7. Foucault M. Nietzsche, a Genealogia e a História. In: Foucault M. Microfísica do Poder. 15a Edição. Rio de Janeiro: Edições Graal; 2000. p. 15-37.

8. Pyl B. Grupo José Pessoa é envolvido em $3^{\circ}$ caso de trabalho escravo. [artigo na Internet] Repórter Brasil. 2009 Jun 25. [acessado 2009 ago 07]. Disponível em: http://www.reporterbrasil.org.br/exibe.php?id= 1602

9. Dias EC, Hoefel MG. O desafio de implementar as ações de Saúde do Trabalhador no SUS: a estratégia da RENAST. Cien Saude Colet 2005; 10(4):817-828.

10. Brito J. Trabalho e Saúde Coletiva: o ponto de vista da atividade e das relações de gênero. Cien Saude Colet 2005; 10(4):879-890.

11. Berlinguer G. Medicina e Política. Rio de Janeiro, São Paulo: Cebes, Hucitec; 1978. (Coleção saúde em debate).

12. Berlinguer G. A Saúde nas Fábricas. Rio de Janeiro, São Paulo: Cebes, Hucitec; 1983.

13. Oddone I, Marri G, Gloria S. Ambiente de Trabalho: a luta dos trabalhadores pela saúde. São Paulo: Hucitec; 1986.

14. Lacaz FAC. O Campo da Saúde do Trabalhador: Resgatando conhecimentos e práticas sobre as relações trabalho-saúde. Cad Saude Publica 2007; 23(4):757-766.

15. Nogueira DP. Incorporação da Saúde ocupacional à rede primária de saúde. Rev Saude Publica 1984; 18(6):495-509.

16. Brasil. Constituição da República Federativa do Brasil de 1988. Diário Oficial da União 1988; 6 out.

17. Brasil. Lei 8.080 de 19 de setembro de 1990. Dispõe sobre as condições para a promoção, proteção e recuperação da saúde, a organização e o funcionamento dos serviços correspondentes e dá outras providências. Diário Oficial da União 1990; 20 set.
18. Vasconcellos LCF. Saúde, trabalho e desenvolvimento sustentável: apontamentos para uma política de Estado [tese]. Rio de Janeiro: Escola Nacional de Saúde Pública, Fundação Oswaldo Cruz; 2007.

19. Brasil. Portaria no 1.679 de 19 de Setembro de 2002. Dispõe sobre estruturação da rede nacional de atenção integral à saúde do trabalhador no SUS e dá outras providências. Diário Oficial da União 2002; 20 set.

20. Brasil. Portaria no 2.437 de 7 de Dezembro de 2005. Dispõe sobre a ampliação e fortalecimento da Rede Nacional de Atenção Integral à Saúde do Trabalhador - RENAST no sistema único de saúde - SUS e dá outras providências. Diário Oficial da União 2005; 7 dez.

21. Brasil. Portaria no 2.728 de 11 de Novembro de 2009. Dispõe sobre a Rede Nacional de Atenção Integral à Saúde do Trabalhador (RENAST) e dá outras providências. Diário Oficial da União 2009; 12 nov.

22. Lourenço EAS, Bertani IF. Saúde do trabalhador no SUS: Desafios e perspectivas frente á precarização do trabalho. Rev. Bras Saude Ocupac 2007; 32(115):121134.

23. Linz LC, Pessanha MFV, Duncan RF, Vasconcelos VT. Acidentes de trabalho no município de Campos dos Goytacazes - RJ, 1995 [monografia]. Campos dos Goytacazes: Programa de saúde do trabalhador; 1997.

24. Campos dos Goytacazes. Secretaria Municipal de Saúde (SMS). I Conferência Municipal de Saúde Propostas Aprovadas. Campos dos Goytacazes: SMS; 1991.

25. Campos dos Goytacazes. Secretaria Municipal de Saúde (SMS). II Conferência Municipal de Saúde Propostas. Campos dos Goytacazes: SMS; 1993.

26. Campos dos Goytacazes. Lei no 6397 de 10 de Setembro de 1997. Autoriza o Chefe do Poder Executivo a instituir o Programa de Saúde do Trabalhador nos termos da Lei no 8080 de 19/09/90 e dá outras providências. Diário Oficial do Município 1997; 10 set.

27. Campos dos Goytacazes. Secretaria Municipal de Saúde (SMS). Programa de Saúde do Trabalhador. Campos dos Goytacazes: SMS; 1998.

28. Brasil. Portaria no 614 de 17 de agosto de 2006. Habilita Centros de Referência em Saúde do Trabalhador - CEREST. Diário Oficial da União 2006; 20 set.

29. Estado do Rio de Janeiro. Secretaria de Saúde e Defesa Civil (SESDEC). Relatório do I Encontro Regional da Saúde do Trabalhador do Norte Fluminense. Rio de Janeiro: SESDEC; 2008.

30. Brasil. Ministério da Saúde. Portaria nº 777 de 28 de abril de 2004. Dispõe sobre os procedimentos técnicos para a notificação compulsória de agravos à saúde do trabalhador em rede de serviços sentinela específica, no Sistema Único de Saúde - SUS. Diário Oficial da União 2004; 29 abr.

31. Monteiro A, Coimbra C, Filho MM. Estado democrático de direito e políticas públicas: estatal é necessariamente público? Psicol Soc 2006; 18(2):7-12.

Artigo apresentado em 10/09/2011

Aprovado em 10/10/2011

Versão final apresentada em 12/10/2011 